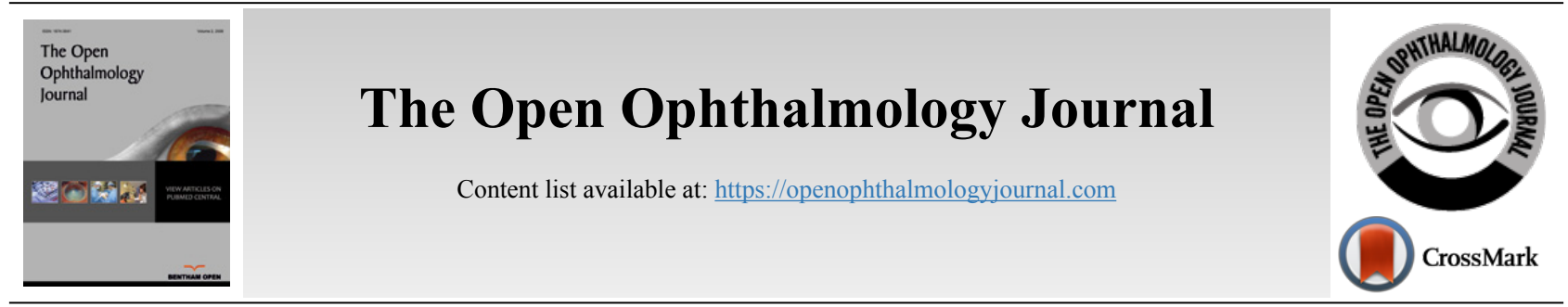

RESEARCH ARTICLE

\title{
Clinical Evaluation of Dry Eye Syndrome in Patients with Proliferative Diabetic Retinopathy and Laser Therapy Indication
}

Barbara de Araujo Lima Dutra ${ }^{1}$, Carolina Lyra Barreira Carneiro ${ }^{1}$, Mariana Studart Mendonça Gomes ${ }^{1,2}$, Rodrigo Dantas Nagashima ${ }^{1}$, Andre Juca Machado ${ }^{1,3}$ and Joao Crispim ${ }^{1,2, *}$

${ }^{1}$ Department of Ophthalmology, Instituto Cearense de Oftalmologia, R. Barão de Aracati 1280, Brazil

${ }^{2}$ Department of Ophthalmology, Centro Universitario Christus, R. João Adolfo Gurgel, 133 - Cocó, Fortaleza - CE, 60190-060, Brazil

${ }^{3}$ Department of Ophthalmology, Universidade Federal do Ceara, R. Costa Mendes 1608, Brazil

\section{Abstract: \\ Background:}

Studies have shown a higher incidence of dry eye among patients with diabetes compared to patients without diabetes. However, information regarding dry eye in patients with proliferative diabetic retinopathy and laser therapy indication is not sufficient.

Objective:

To estimate the clinical manifestation of dry eye syndrome in patients with proliferative diabetic retinopathy and laser therapy indication.

Method:

A cross-sectional study was performed during a local evaluation campaign of diabetic patients with vision disabilities at the Instituto Cearense de Oftalmologia in Fortaleza, CE, Brazil. Patients with proliferative diabetic retinopathy and laser therapy indication were included in the study. An anamnesis directly to dry eye complaints was performed, and eligible participants completed the Ocular Surface Disease Index (OSDI) questionnaire. The slit lamp examination was performed with fluorescein staining; the tear break-up time (TBUT) was measured, and conjunctiva and corneal was evaluated using Rose Bengal (RB) staining. Finally, the Schirmer I test was performed.

Results:

Twenty-five patients were included in the study with a diagnostic time of Diabetes Mellitus ranged from 1 to 35 years, with an average of $17.2 \pm$ 8.7 years. In our sample, 14 patients $(56 \%)$ reported glycemic control with insulin, while 11 patients (44\%) had oral hypoglycemic agents. The most prevalent complaint was blurred vision ( $96 \%$ of patients) followed by low visual acuity $(92 \%)$. A less prevalent complaint was pain (44\%). The mean OSDI score was $49.4 \pm 24.2$. TBUT was less than 10 seconds in 21 patients $(84 \%)$, and RB staining grade was more than 3 in 13 patients $(52 \%)$. The results of the Schirmer I test ranged from 2 to $35 \mathrm{~mm}$, with a mean of $13.57 \pm 9.78 \mathrm{~mm}$. It was smaller than $10 \mathrm{~mm}$ in 15 patients $(60 \%)$.

Conclusion:

The frequency of manifestation of dry eye syndrome was very common in patients with proliferative diabetic retinopathy and laser therapy indication. Ocular surface care should be provided for those patients with significant ocular morbidity.

Keywords: Diabetes mellitus, Dry eye syndrome, Diabetic retinopathy, Laser photocoagulation, Laser therapy, OSDI.

Article History

\section{INTRODUCTION}

Diabetic Retinopathy (DR) is the most common complication of Diabetes Mellitus (DM) and a leading cause of preve-

\footnotetext{
Address correspondence to this author at the Department of Ophthalmology, Centro Universitario Christus, R. João Adolfo Gurgel, 133 - Cocó, Fortaleza CE, 60190-060, Brazil; Tel: +5585999241708; E-mail: joaocrisp@gmail.com
}

ntable blindness. Currently, DR is the leading cause of visual impairment in people of working age in the world [1]. After 20 years of illness, approximately $90 \%$ of people with type 1 diabetes with and $60 \%$ of those with type 2 diabetes develop some degree of retinopathy [2]. The presence of retinopathy is an early marker of microvascular complications. It can be cla- 
Table 1. Inclusion and exclusion criteria for entry into study.

\begin{tabular}{|c|c|}
\hline Inclusion & Exclusion \\
\hline $\begin{array}{c}\text { Proliferative diabetic retinopathy and laser therapy indication } \\
\text { (panretinal photocoagulation) }\end{array}$ & $\begin{array}{c}\text { Non proliferative or proliferative diabetic retinopathy without laser therapy } \\
\text { indication }\end{array}$ \\
\hline Between 18 and 85 years old & $\begin{array}{c}\text { Has any active ocular disease, infection } \\
\text { or allergies }\end{array}$ \\
\hline & $\begin{array}{c}\text { Has a systemic condition or taking medications that may affect a study } \\
\text { outcome variable }\end{array}$ \\
\hline
\end{tabular}

ssified into non-proliferative (mild, moderate and severe) and proliferative [3]. Proliferative diabetic retinopathy starts with a progressive reduction in perfusion of the capillary bed in the retina. Neovascularization develops to compensate for this retinal ischemia [4].

Dry eye is a multifactorial disease of the ocular surface. It is characterized by the loss of tear film homeostasis and is accompanied by ocular symptoms in which tear film instability and hyperosmolarity, ocular surface inflammation and neurosensory abnormalities play etiological roles [3]. Nowadays, Dry Eye Syndrome (DES) is classified as evaporative and/or lacrimal aqueous layer deficiency (excess evaporation due to deficiency of the lipid layer). Due to its negative influence on the visual function and quality of life of patients, dry eye imposes a significant burden on public health [5]. The tests for this diagnosis evaluate the stability of Tear Break-Up Time (TBUT), aqueous layer and lacrimal exchange (Schirmer test, fluorescein clearance, red phenol test and fluorophotometry), alteration of the ocular surface (dyes such as rose bengal and cytology) and qualitative analysis of the tear film (osmolarity and protein analysis) [6]. Several tests are necessary to optimize the diagnosis of dry eye, as well as a symptom questionnaire [7].

Studies have shown a higher incidence of dry eye among the patients with diabetes compared with patients without diabetes [8]. However, information about dry eye in patients with proli-ferative diabetic retinopathy and laser therapy indication, particularly panretinal Photocoagulation (PRP), is not sufficient.

The present study was performed to estimate the clinical manifestation of dry eye syndrome in patients with proliferative diabetic retinopathy and laser therapy indication during a local evaluation campaign at the Instituto Cearense de Oftalmologia. Patients with diabetes were invited to participate in a consultation to assess visual acuity.

\section{MATERIALS AND METHODS}

\subsection{Study Design}

A cross-sectional study was conducted at the Instituto Cearense de Oftalmologia in Fortaleza, CE, Brazil during a local evaluation campaign of patients with diabetes and vision disabilities in March 2018. The hospital ethics committee approved this cross-sectional study, which followed the tenets of the Declaration of Helsinki. Patients screened with proliferative diabetic retinopathy and laser therapy indication were invited to participate (Table 1).

After informed consent was obtained and detailed expl- anation of the present study was provided, an initial clinical evaluation was performed, with anamnesis and complete ophthalmologic examination (Fig. 1).

\subsection{Data Collection}

The anamnesis was directed to complaints of ocular pain and burning, tearing, blurred vision, photophobia, foreign body sensation or ocular dryness, weight on the eyelids and conjunctival hyperemia. Besides, patients were subjected to the Ocular Surface Disease Index () questionnaire. The OSDI is a questionnaire with 12 questions that are graded from 0 (zero) to 4. The total value ranges from 0 (zero) to 100 in which higher scores indicate more severe symptoms. Its final value is calculated by (sum of all scores) X 25 / number of questions answered [9]. below are the questions that constitute the questionnaire: Have you experienced any of the following during the last week? Eyes that are sensitive to light, Eyes that felt gritty, Painful or sore eyes, Blurred vision, Poor vision; Have problems with your eye limited you in performing any of the following during the last week? Reading, driving at night, working with a computer or bank machine (ATM), Watching $\mathrm{TV}$; Have your eyes felt uncomfortable in any of the situations during the last week? Windy conditions, Places or areas with low humidity (very dry), Areas that are air-conditioned.

A slit lamp examination was performed, with particular attention to the ocular surface, composition, and size of the tear meniscus, changes in the palpebral margin, conjunctiva, and cornea.

Initially, the Tear film Break-Up Time (TBUT) was measured with instillation of a drop of sodium fluorescein $0.25 \%$ and consecutively a slit lamp exam with cobalt blue light was performed, to measure the time for the occurrence of the first dry spot of the tear film in the cornea in both eyes. Values less than 10 seconds were considered positive indicative of dry eye.

Afterward, one drop of rose bengal $1 \%$ eyedrop was instilled in the lower fornix of both eyes. The location and intensity of cornea coloration and the nasal and temporal conjunctivae were evaluated. A numerical scale quantified the impregnation of these three areas in each region, ranging from 0-3 (Bijsterveld scale), in which: 0 means absence of staining, 1 means punctate staining, 2 means staining with confluent points, and 3 means staining of large plaques. Scores greater than or equal to 3 were considered as positive indicative of dry eye [10].

Finally, after 20 minutes, it was performed the Schirmer I test without anesthetic drops. The Schirmer stripswere inserted 
in the inferior conjunctival sac of both eyes for 5 minutes. Measurements smaller than $10 \mathrm{~mm}$ were considered positive indicative of dry eye.

\subsection{Data Analysis}

Descriptional statistics was performed using GraphPad Prism 6 for Mac. The OSDI questionnaire with 12 questions was graded from 0 (zero) to 4 , and the total value ranges from 0 (zero) to 100 in which higher scores indicate severe symptoms. TBUT values less than 10 seconds were considered positive as indicative of dry eye. Rose bengal scores greater than or equal to 3 were considered positive. In Schirmer test, wetting of paper less than $10 \mathrm{~mm}$ after 5 minutes without local anesthesia was considered as abnormal. $P$-value $<0.05$ was considered significant. The statistical tests were applied as appropriate.

\section{RESULTS}

From a total of eighty-three screened patients with diabetese, twenty-five were included in the study (Table 2). Their age ranged from 25 to 82 years old, with a mean of 59.8 \pm 11.6 years old. The ratio between men and women was $1: 1.3$. As for ethnicity, the group was divided into 12 pardos (48\%), 11 whites (44\%), and two blacks (8\%).

Regarding risk factors, our patients answered ques-tions about sun exposure and smoking. However, 9 (36\%) said being ex-smokers, with a smoking load ranging from 2 to 72 years. The mean smoking age was $30.5 \pm 27.21$ years.

The time of diagnosis of Diabetes Mellitus ranged from 1 to 35 years (Table 3 ), with an average of $17.2 \pm 8.7$ years. Other complications were investigated, and only one patient (4\%) had peripheral vasculopathy. In our study, 14 patients (56\%) reported of using insulin for glycemic control, while 11 patients (44\%) reported of using oral hypoglycemic agents for glycemic control.

The mean OSDI score was $49.4 \pm 24.2$. The most prevalent complaint in our study was blurred vision, presented by 24 patients $(96 \%)$, followed by low visual acuity (23 patients: $92 \%$ ), sensitivity to light and foreign body sensation (19 patients: $76 \%$ ). The least prevalent complaint was pain (11 patients: $44 \%$ ). The most challenging activity to be performed was reading (17 patients: 68\%), followed by watching TV (16 patients: 64\%). Driving and using the cash machine was complained by $24 \%$ and $32 \%$ patients, respectively. The discomfort in air-conditioned environments was most mentioned (18 patients: $72 \%$ ), followed by discomfort in wind and low humidity environment (both referred by 14 patients: $56 \%$ ). The results of the questionnaire questions are listed in Table 4.

TBUT was less than 10 seconds (altered) in 21 patients (84\%), and the Rose Bengal test staining was more than 3 in 13 patients $(52 \%)$. The results of the Schirmer I test ranged from 2 to $35 \mathrm{~mm}$, with a mean of $13.57 \pm 9.78 \mathrm{~mm}$. It was smaller than $10 \mathrm{~mm}$ in 15 patients $(60 \%)$. These results are shown in Fig. (2).

Patients with altered TBUT, Rose Bengal and Schirmer I simultaneously have at least ten of the symptoms reported in Table 4; those who had two altered tests had at least nine of the symptoms; only the altered TBUT was sufficient for reporting eight of the symptoms.

\section{DISCUSSION}

Our study showed that twenty-four patients (96\%) had at least one complaint characteristic of dry eye syndrome, and 21 patients $(84 \%)$ had at least one test altered (TBUT). The prevalence of clinical manifestation of dry eye syndrome was higher in the long duration of diabetes. Of the twelve questions asked about dry eye symptoms (Table 4), an average of ten symptoms are found in patients who 35 years of age are over $(83.3 \%)$; patients with 21 to 30 years of disease, have an average of 8 symptoms $(66.6 \%) ; 1$ to 10 years of disease, 6 symptoms (Table $\mathbf{3}$ ).

The mean age of the patients and the time of diagnosis of diabetes were similar to those of other published articles. In Table 5, it is observed, in the last five years, reports on the relationship between diabetes and dry eye syndrome [11].

A cross-sectional study evaluated 99 patients, 61 with type 2 diabetes and 38 in the control group, to assess the possible increase in dry eye frequency in patients with diabetic polyneuropathy. Lacrimal film breaking time, Schirmer I test and corneal sensitivity were evaluated. The diagnosis of dry eye was observed more frequently in the group with diabetic polyneuropathy $(44.4 \%)$ than in the control group (28.9\%). Schirmer I, TBUT, and corneal sensitivity values were also worse in patients with diabetic polyneuropathy. The study suggests a relationship between dry eye and type 2 diabetes in patients with diabetic polyneuropathy due to reduced corneal sensitivity, compromising the balance of tear production and evaporation. Therefore, patients with diabetic polyneuropathy should be screened for dry eye to prevent damage to the ocular surface [17].

Table 2. Patient's demographics.

\begin{tabular}{|c|c|}
\hline Age & 25 to 82 years-old \\
\hline Ethnicity & 12 Pardos, 11 Whites, and 2 Blacks \\
\hline Sun Exposure & 5 Patients \\
\hline Ex-Smokers & 9 Patients \\
\hline Glycemic Control with Insulin & 14 Patients \\
\hline
\end{tabular}


Table 3. Time of diagnosis of Diabetes Mellitus and symptoms of dry eye.

\begin{tabular}{|c|c|c|c|c|}
\hline Time & \multicolumn{2}{|c|}{ Participants } & \multicolumn{2}{c|}{ Average Number of Symptoms } \\
\hline & $\mathbf{N}^{\mathbf{0}}$ & $\mathbf{\%}$ & $\mathbf{N}^{\mathbf{0}}$ & $\mathbf{\%}$ \\
\hline 1- 10 years & 5 & 20 & 5 & 51,6 \\
\hline 11- 20years & 15 & 60 & 8 & 58,3 \\
\hline 21-30 years & 3 & 12 & 10 & 66,6 \\
\hline > 30 years & 2 & 8 & 83,3 \\
\hline
\end{tabular}

Table 4. Summary of participant responses to questions.

\begin{tabular}{|c|c|c|c|c|c|}
\hline \multirow{2}{*}{\multicolumn{2}{|c|}{ Questions }} & \multicolumn{4}{|c|}{$\mathrm{N}^{0}$ of Participants $=25$} \\
\hline & & \multirow{2}{*}{$\begin{array}{c}\begin{array}{c}\mathbf{N}^{0} \text { of } \\
\text { Participants Responding } \\
\text { "Yes" }\end{array} \\
24 \\
\end{array}$} & \multirow{2}{*}{\begin{tabular}{|l|}
$\%$ \\
96 \\
\end{tabular}} & \multirow{2}{*}{$\begin{array}{c}\begin{array}{c}\mathrm{N}^{\mathbf{0}} \text { of } \\
\text { Participants Responding } \\
\text { "No" }\end{array} \\
1 \\
\end{array}$} & \multirow{2}{*}{\begin{tabular}{|l}
$\%$ \\
4
\end{tabular}} \\
\hline \multirow{5}{*}{ Symptoms in the last week } & Blurred vision & & & & \\
\hline & Low visual acuity & 23 & 92 & 2 & 8 \\
\hline & Clarity sensitivity & 19 & 76 & 6 & 24 \\
\hline & Foreign Body Sensation & 19 & 76 & 6 & 24 \\
\hline & Pain & 11 & 44 & 14 & 56 \\
\hline Difficulty in the last & Read & 17 & 68 & 8 & 32 \\
\hline \multirow[t]{3}{*}{ Week } & Watch TV & 16 & 64 & 9 & 36 \\
\hline & Use PC or cash machine & 8 & 32 & 17 & 68 \\
\hline & Drive at night & 6 & 24 & 19 & 76 \\
\hline Discomfort in the & Air conditioning & 18 & 72 & 7 & 28 \\
\hline \multirow[t]{2}{*}{ last week } & Wind & 14 & 56 & 11 & 44 \\
\hline & $\begin{array}{c}\text { Environment with low } \\
\text { Humidity }\end{array}$ & 14 & 56 & 11 & 44 \\
\hline
\end{tabular}

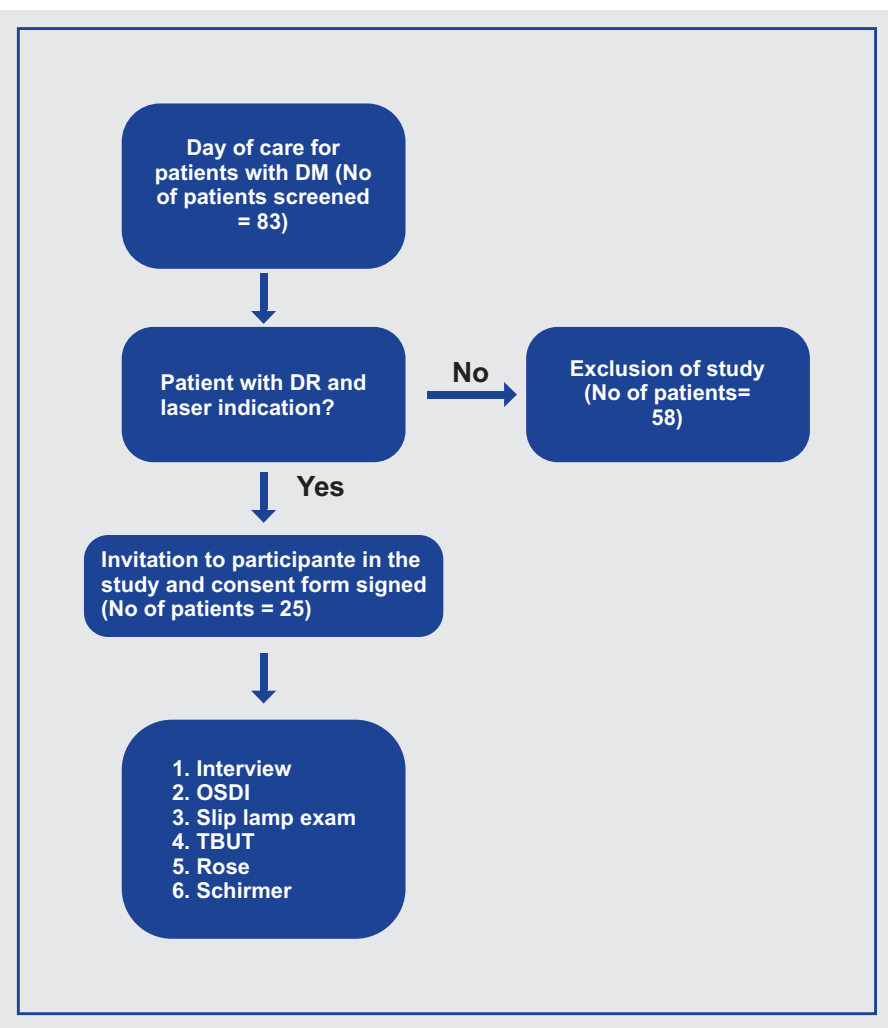

Fig. (1). Flow chart demonstrating the study design. DM: Diabetes Mellitus; No: number; DR: Diabetic Retinopathy; OSDI: Ocular Surface Disease Index; TBUT: tear film break-up time. 


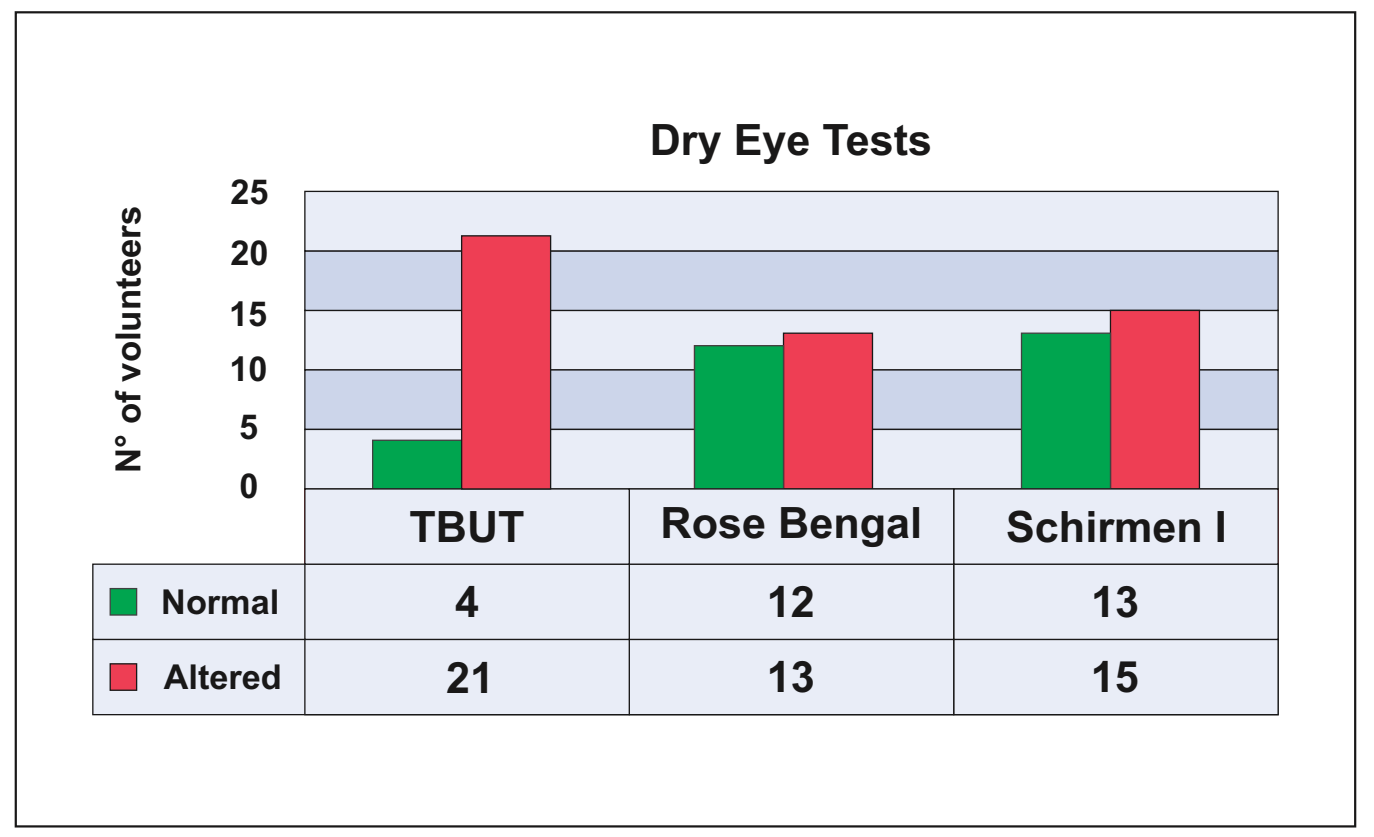

Fig. (2). Results from dry eye tests (TBUT, Rose Bengal, and Schirmer) in subjects with proliferative diabetic retinopathy and laser therapy indication. TBUT: tear film break-up time.

Table 5. Summary of studies showing the association between Dry Eye Syndrome and diabetes mellitus in the last five years.

\begin{tabular}{|c|c|c|}
\hline AUTHORS & TITLE & RESULTS \\
\hline $\begin{array}{l}\text { Zou X, et al }[12] \\
\qquad(2018)\end{array}$ & $\begin{array}{l}\text { Prevalence and clinical characteristics of dry eye disease in } \\
\text { community-based dry eye and diabetes mellitus } 2 \text { diabetic } \\
\text { patients: the } \\
\text { Beixinjing eye study. }\end{array}$ & $\begin{array}{l}\text { Significant association between the presence of dry eye, } \\
\text { higher glycemia and elevation of glycosylated hemoglobin. }\end{array}$ \\
\hline Ma A, et al [13] (2018) & $\begin{array}{c}\text { Association of long-term glycaemic control on tear break-up } \\
\text { times and Determination of Risk Factors and Treatment of } \\
\text { Dry Eye Disease in Type } 1 \text { Diabetes Before Corneal } \\
\text { Complications } \\
\text { at Sindh Institute of Ophthalmology and Visual Sciences. dry } \\
\text { eye symptoms in Chinese patients } \\
\text { with type } 2 \text { diabetes. }\end{array}$ & $\begin{array}{l}\text { Good glycemic control is a modifiable risk factor for both dry } \\
\text { eye and tear film instability in patients with type } 2 \text { diabetes. }\end{array}$ \\
\hline $\begin{array}{l}\text { Shujaat } \mathrm{S} \text {, et al }[14] \\
(2017)\end{array}$ & $\begin{array}{c}\text { Investigation of Ocular Tear Ferning in Controlled and } \\
\text { Uncontrolled Diabetic Subjects. }\end{array}$ & $\begin{array}{l}\text { Acute increase in frequency and risk of developing dry eye } \\
\text { disease in patients with type } 1 \text { diabetes. }\end{array}$ \\
\hline $\begin{array}{c}\text { Al Houssien AO, et al } \\
{[15](2017)}\end{array}$ & $\begin{array}{c}\text { Magnitude of diabetes and hypertension among patients with } \\
\text { Dry Eye Syndrome at a tertiary hospital of Riyadh, Saudi } \\
\text { Arabia - A case series. }\end{array}$ & $\begin{array}{l}\text { Uncontrolled blood glucose levels appeared to be a risk factor } \\
\text { for dry eye syndrome. }\end{array}$ \\
\hline $\begin{array}{l}\text { Kan S, et al }[16] \\
\text { (2017) }\end{array}$ & $\begin{array}{l}\text { The effects of blood glucose regulation on tear function tests } \\
\text { in diabetic patients. }\end{array}$ & $\begin{array}{c}\mathrm{DM} \text { is a hyperosmolar disorder that appears to cause } \\
\text { elevation in the rate of ocular surface disease, especially if } \\
\text { glycemia is poorly regulated. }\end{array}$ \\
\hline $\begin{array}{c}\text { Aljarousha } \\
\text { M, et al }[18](2016)\end{array}$ & $\begin{array}{l}\text { Comparison of Dry Eye Parameters between } \\
\text { Diabetics and Non-Diabetics in District of Kuantan, Pahang. }\end{array}$ & $\begin{array}{l}\text { Dry eye symptoms were significantly associated with } \\
\text { diabetics. }\end{array}$ \\
\hline $\begin{array}{l}\text { Achtsidis } \mathrm{V} \text {, et al }[17] \\
\text { (2014) }\end{array}$ & $\begin{array}{l}\text { Dry eye syndrome in subjects with diabetes and } \\
\text { association with neuropathy. }\end{array}$ & $\begin{array}{l}\text { DES is common in patients with diabetes, } \\
\text { especially in cases of neuropathy, and is associated with } \\
\text { reduced corneal sensitivity. Hypoaesthesia of the cornea } \\
\text { reduces patient symptoms. }\end{array}$ \\
\hline Lv H, et al $[18](2014)$ & $\begin{array}{l}\text { Meta-analysis and review on the changes of tear function and } \\
\text { corneal sensitivity in diabetic patients. }\end{array}$ & $\begin{array}{l}\text { The sensitivity of the cornea was lower in diabetic patients } \\
\text { than in the control group, suggesting worsening of the } \\
\text { lacrimal functions in these patients compared to the control } \\
\text { group. }\end{array}$ \\
\hline \multirow{2}{*}{$\begin{array}{l}\text { Imam S, Elagin RB, } \\
\text { Jaume JC [19] (2013) }\end{array}$} & Diabetes-associated dry eye syndrome in a new & Association of dry eye disease with insulitis and \\
\hline & humanized transgenic model of type 1 diabetes. & clinically relevant diabetes in mice. \\
\hline
\end{tabular}


(Table 5) contd....

\begin{tabular}{|c|c|c|}
\hline AUTHORS & TITLE & RESULTS \\
\hline $\begin{array}{l}\text { Najafi L, et al [20] } \\
\text { (2013) }\end{array}$ & $\begin{array}{c}\text { Dry eye and its correlation to diabetes } \\
\text { microvascular complications in people with type } 2 \text { diabetes } \\
\text { mellitus. }\end{array}$ & $\begin{array}{l}\text { Dry eye disease is common in people with type } 2 \\
\text { diabetes, being more prevalent in people suffering from } \\
\text { advanced stages of diabetic Retinopathy }\end{array}$ \\
\hline
\end{tabular}

Najafi et al. studied 243 patients with type II diabetes. The prevalence of dry eye disease was $27.7 \%$. A significant correlation was found between dry eye disease and diabetic retinopathy $(P=0.01)$, the former being more prevalent in people with proliferative diabetic retinopathy and/or with clinically significant macular edema (0.006). It can thus be concluded that dry eye disease is common in people with type 2 diabetes, especially in those with advanced stages of diabetic retinopathy [20].

Another study performed tests on 100 subjects (50 healthy subjects in the control group and 50 subjects suffering from diabetes) aged between 50-70 years. In the group of diabetic patients $(n=50)$ it was found that $37(74 \%)$ of them had lower values of tear secretion and $23(46 \%)$ had lower values of TBUT. In the control group $(\mathrm{N}=50)$, they found that $28(56 \%)$ presented lower values of lacrimal secretion and 17 (34\%) of them had lower TBUT values [21].

Ma A, et al. [13], as in our study, included in the study time of diagnosis, on average 17 years, the age of patients $65 \pm$ 11 years, and OSDI 16, observing statistical relevance in the last two. The mean levels reported by Kan S, and cols.20 of the OSDI score, the TBUT test, and the Schirmer test were altered after a decrease in glycemic levels, with OSDI ranging from a mean of 28.38 to $17.82(\mathrm{p}<0.05)$. Aljarousha M, et al. [8] observed a higher percentage of dry eye symptoms in diabetics, as well as tear film rupture time significantly different between diabetics and non-diabetics. Lv H et al [18] evaluated in their meta-analysis that the sensitivity of tear film in diabetic patients is worse in comparison to the control group. They also concluded that diabetic patients with proliferative diabetic retinopathy are more predisposed to impaired tear function and corneal sensitivity and should always be examined for changes in the tear film and ocular surface.

The correlation of dry eye syndrome with gestational diabetes was not well established. It is believed that for the shortest time exposure to hyperglycemia [22].

In our study, the frequency of dry eye syndrome was quite high in diabetic patients with proliferative diabetic retinopathy and an indication of laser therapy, but we did not find a similar study, and there is a greater need for studies to evaluate the relationship between dry eye and proliferative diabetic retinopathy with the indication of laser therapy.

The study presented has limitations on the size and followup of the sample, which, when showing in a reduced number, allows to consider the results found only for the population in question. Also, the lack of a control group and the evaluation of blood glucose levels, mainly through quantification of $\mathrm{HbA1C}$, may be mentioned as limitations of our study too.

\section{CONCLUSION}

The prevalence of dry eye in our study is very high. There is also the possibility that dry eye syndrome is due to the physiological aging process, the dry weather in the region and the high prevalence of neurological impairment in type 2 diabetic patients.

\section{ETHICS APPROVAL AND CONSENT TO PART- ICIPATE}

The study was approved by the ethics committee of Center of Ophthalmology.

\section{HUMAN AND ANIMAL RIGHTS}

No Animals were used in this research. All human research procedures followed were in accordance with the ethical standards of the committee responsible for human experimentation (institutional and national), and with the Helsinki Declaration of 1975, as revised in 2013.

\section{CONSENT FOR PUBLICATION}

An informed written consent was obtained from all the patients when they were enrolled.

\section{CONFLICT OF INTEREST}

The authors declare no conflict of interest, financial or otherwise.

\section{ACKNOWLEDGEMENTS}

Declared none.

\section{REFERENCES}

[1] Caglar C, Demir E, Kucukler FK, Durmus M. A bibliometric analysis of academic publication on diabetic retinopathy disease trends during 1980-2014: A global and medical view. Int J Ophthalmol 2016; 9(11): 1663-8. [PMID: 27990373]

[2] Ting DS, Cheung GC, Wong TY. Diabetic retinopathy: Global prevalence, major risk factors, screening practices and public health challenges: A review. Clin Experiment Ophthalmol 2016; 44(4): 260-77.

[http://dx.doi.org/10.1111/ceo.12696] [PMID: 26716602]

[3] Said AM, Farag ME, Abdulla TM, Ziko OA, Osman WM. Corneal sensitivity, ocular surface health and tear film stability after punctal plug therapy of aqueous deficient dry eye. Int J Ophthalmol 2016; 9(11): 1598-607.

[PMID: 27990362]

[4] Zeev MS, Miller DD, Latkany R. Diagnosis of dry eye disease and emerging technologies. Clin Ophthalmol 2014; 8: 581-90. [PMID: 24672224]

[5] Foulks GN, Forstot SL, Donshik PC, et al. Clinical guidelines for management of dry eye associated with Sjögren disease. Ocul Surf 2015; 13(2): 118-32.

[http://dx.doi.org/10.1016/j.jtos.2014.12.001] [PMID: 25881996]

[6] Aljarousha M, Badarudin NE, Che Azemin MZ. Comparison of dry eye parameters between diabetics and non-diabetics in district of Kuantan, Pahang. Malays J Med Sci 2016; 23(3): 72-7. [PMID: 27418872]

[7] Schiffman RM, Christianson MD, Jacobsen G, Hirsch JD, Reis BL. Reliability and validity of the ocular surface disease index. Arch Ophthalmol 2000; 118(5): 615-21.

[http://dx.doi.org/10.1001/archopht.118.5.615] [PMID: 10815152]

[8] Klaassen-Broekema N, Mackor AJ, van Bijsterveld OP. The diagnostic power of the tests for tear gland related keratoconjunctivitis 
sicca. Neth J Med 1992; 40(3-4): 113-6. [PMID: 1603200]

[9] Ding J, Liu Y, Sullivan DA. Effects of insulin and high glucose on human meibomian gland epithelial cells. Invest Ophthalmol Vis Sci 2015; 56(13): 7814-20.

[http://dx.doi.org/10.1167/iovs.15-18049] [PMID: 26658502]

[10] Zou X, Lu L, Xu Y, et al. Prevalence and clinical characteristics of dry eye disease in community-based type 2 diabetic patients: The Beixinjing eye study. BMC Ophthalmol 2018; 18(1): 117. [http://dx.doi.org/10.1186/s12886-018-0781-7] [PMID: 29747621]

[11] Ma A, Mask MS, Shin KC, et al. Association of long-term glycaemic control on tear break-up times and dry eye symptoms in Chinese patients with type 2 diabetes. Clin Exp Ophthalmol 2018 Jan 18. [http://dx.doi.org/10.1111/ceo.13146]

[12] Shujaat S, Jawed M, Memon S, Talpur KI. Determination of risk factors and treatment of dry eye disease in type 1 diabetes before corneal complications at sindh institute of ophthalmology and visual sciences. Open Ophthalmol J 2017; 11: 355-61.

[http://dx.doi.org/10.2174/1874364101711010355] [PMID: 29299082]

[13] Al Houssien AO, Al Houssien RO, Al-Hawass A. Magnitude of diabetes and hypertension among patients with dry eye syndrome at a tertiary hospital of Riyadh, Saudi Arabia - A case series. Saudi J Ophthalmol 2017; 31(2): 91-4.

[http://dx.doi.org/10.1016/j.sjopt.2017.02.001] [PMID: 28559720]

[14] Kan S, Acar U, Kizilgul M, et al. The effects of blood glucose regulation on tear function tests in diabetic patients. J Fr Ophtalmol 2017; 40(6): 499-504.

[http://dx.doi.org/10.1016/j.jfo.2016.10.019] [PMID: 28502385]
[15] Achtsidis V, Eleftheriadou I, Kozanidou E, et al. Dry eye syndrome in subjects with diabetes and association with neuropathy. Diabetes Care 2014; 37(10): e210-1.

[http://dx.doi.org/10.2337/dc14-0860] [PMID: 25249675]

[16] Lv H, Li A, Zhang X, et al. Meta-analysis and review on the changes of tear function and corneal sensitivity in diabetic patients. Acta Ophthalmol 2014; 92(2): e96-e104.

[http://dx.doi.org/10.1111/aos.12063] [PMID: 23782539]

[17] Imam S, Elagin RB, Jaume JC. Diabetes-associated dry eye syndrome in a new humanized transgenic model of type 1 diabetes. Mol Vis 2013; 19: 1259-67.

[PMID: 23805032]

[18] Najafi L, Malek M, Valojerdi AE, et al. Dry eye and its correlation to diabetes microvascular complications in people with type 2 diabetes mellitus. J Diabetes Complications 2013; 27(5): 459-62.

[http://dx.doi.org/10.1016/j.jdiacomp.2013.04.006] [PMID: 23726741]

[19] Manaviat MR, Rashidi M, Afkhami-Ardekani M, Shoja MR. Prevalence of dry eye syndrome and diabetic retinopathy in type 2 diabetic patients. BMC Ophthalmol 2008; 8(10): 10.

[http://dx.doi.org/10.1186/1471-2415-8-10] [PMID: 18513455]

[20] Najafi L, Malek M, Valojerdi AE. Dry eye and its correlation to diabetes microvascular complications in people with type 2 diabetes mellitus. J Diabetes Complications 2013; 27(5): 459-62.

[21] Manaviat M R, Rashidi M. Prevalence of dry eye syndrome and diabetic retinopathy in type 2 diabetic patients. BMC Ophthalmol 2008; 8(10): 1-4.

[22] Kan S, Acar U, Kizilgul M. Tear Film and Ocular Surface Evaluation in Gestational Diabetes Mellitus. SeminOphthalmol 2018; 33(3): 402-6.

\section{C) 2019 Dutra et al.}

This is an open access article distributed under the terms of the Creative Commons Attribution 4.0 International Public License (CC-BY 4.0), a copy of which is available at: (https://creativecommons.org/licenses/by/4.0/legalcode). This license permits unrestricted use, distribution, and reproduction in any medium, provided the original author and source are credited. 